Self-Help and the Surfacing of Identity: Producing the Third Culture Kid

\title{
Self-Help and the Surfacing of Identity: Producing the Third Culture Kid
}

\begin{abstract}
In this paper, I argue for a need to expand our understanding of the role that self-help plays in the constitution of identities. Using the example of the Third Culture Kid (TCK) industry, I argue that self-help acts as a space of biopower through its role in managing the emotional experience of having been globally mobile as a child. To do this, the paper looks at how the TCK, as a subject, is surfaced as comfort in relation to the ascribed grief and insecurity of identity that is associated with childhood global mobility. Data are derived from a multi-sited ethnography, including a narrative analysis of TCK literature, reader discussions, participant observation at a TCK event and an online survey. The argument contributes to scholarly critiques of self-help by examining processes of production and consumption of TCK subjectivity enacted through the TCK industry. Thereby, the paper contends that in researching self-help we need a wider understanding of its production and consumption, how people are persuaded to use it, and how they respond to ideas presented within it.
\end{abstract}

Key words: self-help, subjectivity, identity, Third Culture Kids, comfort, grief 
Self-Help and the Surfacing of Identity: Producing the Third Culture Kid

\section{Introduction}

This paper argues that we need to think more widely about how self-help plays a role in the constitution of identities. Self-help acts as guidance towards self-improvement in different forms, from books to websites to support groups; it is an industry that was worth an estimated $\$ 11$ billion in the US in 2013 (Groskop, 2013). Yet, in spite of this, self-help has received scant attention within the social sciences. The few exceptions include Rimke (2000) on the neoliberal self, Davidson (2001) on agoraphobic self-help groups, Hazelden (2003) on relationship manuals, McGee (2005) on self-invention for the labour market, and Sothern $(2007 ; 2011)$ on disabled sex and organ transfer (with Dickenson).

This existing work on self-help illustrates how it works within Foucauldian understandings of governmentality to produce a normalised self or subject. The management of the self is the focus of analysis, where 'a very particular type of citizen capable of living a particular type of public life is produced by self-help' (Hazleden, 2003, p. 425; emphasis in original). The central concern of this work is to explore how the self is produced as part of wider discourses of power, looking in particular at the role that neoliberal governance plays within this, recognising that neoliberalism has 'new requirements of self-responsibility by individual subjects' (Ong, 2007, p. 4). Through this paper, I extend this argument in two ways. First, I argue that self-help works by governing subjectivity through managing emotions - a form of biopower. Second, I argue that we need a wider understanding of the consumption of self-help: how are people persuaded to use self-help? How do they respond to the ideas presented within it?

To do so, the paper uses a case study of the Third Culture Kid (TCK) industry. TCK is a name given to a child (or adult as ATCK) who has spent a 'significant part of his or her developmental years outside the parent's culture' (Pollock \& Van Reken, 2009, p. 13). Third culture refers to an international culture that is placeless. The first culture is the parent's culture; the second is the culture of the country the child is living in; and the third is described as an 'interstitial' culture, a 
Self-Help and the Surfacing of Identity: Producing the Third Culture Kid

'culture between cultures' (Pollock \& Van Reken, 2009, p. 14). This understanding of personal cultural identity that the TCK industry produces is clearly simplistic, particularly in terms of thinking about contemporary societies and global mobility patterns. This is, in part, due to the fact that the term TCK has a popular usage, but has not been the subject of significant academic research, as Fechter and Korpela (2016, p. 423) argue: 'although the term seems to work as a descriptive label and it is popular outside of academia, it runs into trouble when used analytically because, among others, of the homogenizing, American-centric approach on which it was developed and its very essentializing view of cultures.' However, my interest in this paper is how the TCK industry acts as a self-help industry, and therefore the problematic nature of this term will not be the focus of study. Instead, my concern is why the term TCK has significant purchase amongst people who have been globally mobile as children, or why it is 'popular.' I argue that the experience of being globally mobile as a child is seen to evoke a particular response: 'there is something about growing up in and among cultures that creates an emotional experience' (Pollock \& Van Reken, 2009, p. 18). The TCK industry acts as the manager of this emotional experience, producing, disseminating and selling knowledge on the best practices of helping people who have been globally mobile as children. The paper will focus on the ways in which grief and insecurity are produced as the normal response to having been globally mobile as a child by the TCK industry, framed as a condition of liminality. This liminality, as the paper will show, is a form of insecurity of being-in-the-world, or ontological insecurity. The TCK industry, then, produces a narrative through which people who have had a globally mobile childhood 'discover' their TCK self and, in doing so, find a comfort in belonging.

The paper is structured as follows. The next section outlines theorisations of the subject, arguing that self-help acts as a form of the psy-disciplines, directing the individual through claiming authority on knowing self-help. Section 3 provides a methodological note. Section 4 explores the TCK industry, examining how authority to know the TCK is produced through claiming 
Self-Help and the Surfacing of Identity: Producing the Third Culture Kid

expertise, and how this knowledge of a normal emotional response to childhood global mobility works to surface the TCK self. Section 5 provides some conclusions, arguing the paper illustrates how the TCK industry can help us understand self-help as a space in which emotional registers of belonging are produced and managed.

\section{Governance of the Self}

The paper follows other work on the governance of the self by utilising a Foucauldian understanding of the subject. That is, the subject, or I, is produced and regulated through power, and is 'not really a pre-existing thing,' but rather a way in which 'we are led to think about ourselves' (Mansfield, 2000, p. 10). With Foucault's (2007) understanding of disciplinary power we can see the ways in which individuals are compared and hierarchized, and normal and abnormal are produced. For example, Sothern (2007) highlights how self-help manuals for disabled sex work reproduce normative assumptions of sexuality, with the self-help book working to teach the reader what these are and how they can be given expression. Through biopower, the population is seen as a resource that must be protected, supervised and improved; where, for the optimal norm, you can 'identify a number of modifiable variables on which it depends' (Foucault (2007, p. 74). Biopower, then, can be seen as control over life, including emotions. Anderson (2011) indicates that biopower operates as a form of power in two ways. First, it requires an object to refer to, an aspect of life which we have knowledge about. Second, it acts as an intervention, working to improve that aspect of life against a threat (p. 30). In this paper, the object of the TCK industry is the (potentially destabilising) emotional experience of having been globally mobile as a child, with the TCK industry producing knowledge of this aspect of life. The industry works to intervene, by offering a new self, the TCK.

However, while the formulation and characteristics of neoliberal selves in self-help have been the subject of previous research (Rimke, 2000; Sothern, 2007; Sothern \& Dickinson, 2011), what is 
Self-Help and the Surfacing of Identity: Producing the Third Culture Kid

missing from these accounts is a wider understanding of the relationship between the subject offered by self-help and the ways in which this is utilised as an identity-that is, the reader of self-help remains imaginary. In this paper, I address this gap by looking at the production and consumption of TCK subjectivity through the TCK industry.

To examine the ways in which people are persuaded to consume the ideas within self-help, I draw upon understandings of the psy-disciplines. In developing Foucault's theorisations of power, Rose (1999) looks at the ways through which people are persuaded to regulate their selfhoods. He argues that psy-disciplines produce knowledge about the self, acting both as the 'expertise of subjectivity' (Rose, 1999, p. 3) and to produce technologies of the self, methods through which the self can be individually modified. Importantly, within this, Rose illustrates that people are persuaded to use technologies of the self because they are advocated by experts, a 'claim to social authority' (1999, p. 3). In this way, Rose addresses the issue of interpellation, the mechanism by which people take up subject positions. In theorisations of the subject, Althusser argued that individuals are actively constituted as subjects through ideology, as a set of practices which engage us and in which we are engaged (Probyn 2003). The example used to illustrate this is a policeman hailing someone on the street, that 'by calling out to him, the policeman creates from the solitary walker in the street a certain type of subject-one answerable to the law and to the state and the system behind it' (Mansfield, 2000, p.53). Thus through ideological state apparatuses, we derive an understanding of what it is to be a citizen and thereby bear ideologywe are interpellated. Ahmed (2006) advances this by highlighting the importance of direction: 'the question of direction is crucial to the emergence of subjectivity and the "force" of being given a name' (p. 15). That is, the individual is directed towards the norm by societal pressures. The psy-disciplines, as a 'claim to social authority', act as this direction, the 'means of the languages, criteria, and techniques offered to us, to act upon our bodies, souls, thoughts and conduct' (Rose, 1999, p. 11). 
Self-Help and the Surfacing of Identity: Producing the Third Culture Kid

In the paper, I show how the TCK industry acts as a mechanism through which the TCK subject is interpellated, in that it acts as a space of biopower. Self-help can be seen to act as technologies of the self, whereby they 'assist subjects in arriving at their own diagnosis and treatment' (2000, p. 62). I argue, then, it is by looking at how people are persuaded to use self-help through claims to authority that we can explore why some of the ideas presented within self-help have traction. In this way, understanding how people respond to self-help also becomes important, as Davidson highlights that 'membership of the self-help group could itself become an important factor in mediating the ... sense of self and group identity' (2001, p. 166). That is, for our understanding of self-help, we need to understand where the ideas of the self come from, and what the response is to them.

\section{Methods}

The paper utilises a multi-sited ethnography that sought to 'follow' the production and consumption of the TCK. For Marcus (1995), a multi-sited ethnography is 'designed around chains, paths, threads, conjunctions or the juxtaposition of locations' in and through which one follows the object of research. The TCK industry itself operates in and at a variety of spaces and scales, for example, including people who blog about their experiences, individuals operating out of home offices, authors writing books, to larger-scale service providers and conferences. Like other self-help industries, the TCK industry can be challenging to conceptualise due to the multiple people or actors that identify themselves as being involved. However, the paper focuses on the main reported purpose that unites the actors involved in the TCK industry: providing services that assist people who are, or have been, globally mobile as children. In this way, following is an appropriate method as it allows for an understanding of how the sites are connected with one another in such ways that relationships between them are as important for 
Self-Help and the Surfacing of Identity: Producing the Third Culture Kid

this formulation as the relationships within them; the fields are not some mere collection of local units' (Hannerz, 2003, p. 206).

The paper utilises four ethnographic methods to employ this reading of the TCK industry. First, narrative analysis of key textual artefacts of the TCK industry, for example, key self-help books, newsletters of industry players, blog posts and so on. These artefacts were selected on the basis of the frequency of reference to them in different parts of the TCK industry. Second, an analysis of online discussions of the primary TCK book: Third Culture Kids: Growing up Between Worlds (discussed below). The data are derived from a book group discussion of the book hosted on the website Good Reads (at date of analysis in July 2015, 341 comments) and reviews written of the book on Good Reads and Amazon (129 and 132 reviews respectively). The discussions and reviews of the book allow us to see the ways in which the audience responds to the ideas presented in it. The reviews were analysed through narrative analysis, looking for a repetition of themes about TCK which were coded, how these codes connected to one another and how they were constructed in reference to other aspects of the TCK industry. Third, the paper draws upon participant observation at the key TCK industry event in March 2015. This event was designed to share best practices in helping people who have been globally mobile as a child. Fourth, the paper utilises responses to an in-depth survey carried out in summer 2015, which looked at the emotional impact of having been globally mobile as a child. ${ }^{1}$ Posted on Facebook and Twitter to capture the global audience of TCKs, the survey with open-ended questions gathered 30 responses, and explored how and why people identified themselves as TCKs. This survey acted to triangulate ideas from the online discussion forums and TCK industry event. Although these methods do not allow for a linearity in understanding the relationship between engaging with the

\footnotetext{
${ }^{1}$ I was born outside my passport country, which means I would qualify as a TCK. Also at the time I carried out this research, I was undergoing significant personal change, which meant that I could identify with the issues of grief and insecurity that are outlined by the TCK industry. However, I would not use this term to identify myself as I think the term is too simplistic to describe my identity.
} 
Self-Help and the Surfacing of Identity: Producing the Third Culture Kid

TCK industry and the active identification with the term, it allows us to see the ways in which an ' $\mathrm{I}$ ' is produced through discourse and how this related to the ' $\mathrm{I}$ ' that is articulated by individuals.

This acts as a way in which we can extend our understanding of the sites through which identity is produced, challenging place-based accounts to think more broadly about how identities and are produced in sites which do not necessarily have a specific location (see also Cranston 2016).

\section{Authority, Liminality and the Surfacing of the TCK}

The following sections analyse and discuss how self-help works through the governing of emotions - in this case, how the TCK industry works to govern the emotions associated with having been globally mobile as a child. In doing so, it looks first at how people are persuaded to use the TCK industry, through the claiming of expertise on knowing this experience. Second, it explores how the TCK industry produces a norm of the emotional response to childhood global mobility as being insecurity and grief associated with a liminality of a national identity. Third, it examines the ways in which people respond to the ideas presented through the TCK industry, arguing that they find a comfort in a collective identification with being TCKs.

\section{Authority and the TCK Industry}

In researching self-help we need to understand the ways in which it acts as expertise in knowing the self. As noted above, Ahmed (2006) finds the question of direction important. Self-help acts as a form of psy-discipline, through claims to expertise on knowing the self that direct individuals to a version of the self. One of the central ways in which self-help works as a facet of biopower is that it highlights a self that an individual can be-a method through which the self 
Self-Help and the Surfacing of Identity: Producing the Third Culture Kid

can be improved, and one that is also persuasive to the reader. As Rimke contends, self-help is contingent upon a person's seeking some external form of authoritative assistance' (2000, p. 62). Being persuaded or having authority arguably comes from expertise. To explore expertise then we must look at the 'background of practices and the social, material, spatial, organizational, and conceptual arrangements that serve as its conditions of possibility' (Eyal, 2013, p. 871).

Therefore, we can think about the ways in which expertise is 'assembled' as part of the TCK industry (Eyal, 2013). The industry has its clearest expression in the book: Third Culture Kids: Growing up Between Worlds (referred to as 'the book' for the rest of the paper) written by David Pollock C. Pollock and Ruth Van Reken. The background of this book is also the background of the industry, whereby the book acts as its 'powerful representative' (Barnes, 2002, p. 492). We can see how this is expressed through frequent references to the TCK book being 'the Bible equivalent for TCKs' (SR, Amazon Review, November 2013). As a representative of the TCK industry, the TCK book acts as rhetoric, becoming difficult to argue against because it draws together a number of allies, such as people, spaces and ideas of the TCK industry (c.f. Barnes, 2002). It becomes an 'obligatory passage point' where 'anyone wanting to do anything in the discipline [or industry] needs to make some reference to such points if they are both to be taken seriously, and do the things that they claim to do' (Barnes, 2002, p. 494). That is, for anyone working within the TCK industry, they need to engage with the ideas within the book as this is seen as the definitive and authoritative source for understanding TCKs.

The desire to help TCKs adjust to the emotional challenges associated with being globally mobile as a child evolved into an industry in the 1980s, pioneered by Pollock who 'was the person who translated it [TCK] from an academic idea to making a difference in the lives of those who were living it' (Van Reken, 2014). As the director of Interaction Inc., an organization designed to support the families of people being moved overseas, primarily the children of missionaries, Pollock travelled globally delivering seminars to schools and organizations, and set up 're-entry' 
Self-Help and the Surfacing of Identity: Producing the Third Culture Kid

camps to assist repatriating TCKs, as well as international conferences on this subject. Van Reken was introduced to the term TCK at one of Pollock's conferences in the Philippines. At the time, she was writing her autobiography on having been globally mobile as a child. Her journey to 'discovering' she was a TCK as an adult is well documented: 'Finally writing about her experiences, at 39 years old, helped her process the emotions she had felt growing up as a TCK... "This was not a book about a topic but simply a process of self-discovery," she explained' (Interview with Van Reken, Bertuccelli, 2015, p. 3). In the years after publishing her memoir, while Van Reken received numerous letters from readers who identified with the experiences in the book, she suggested to Pollock that he might want to publish his work before someone else took credit for his ideas (Van Reken, 2012). Van Reken, in offering to help, looked for scientific evidence to support Pollock's theories and the first edition of the book was published in 2001. However, the research evidence base behind the TCK is often unclear-the industry itself actively encourages more work to be carried out in this area (Field notes from event, March 2015, see also Fechter \& Korpela, 2016).

This short history of the TCK book shows how the authority to know the TCK self is based upon the experiential knowledge of knowing the TCK experience as being loss and grief. In Pollock's case, this knowledge is through experience of working with those who have had globally mobile childhoods; in Van Reken's it is based on her own experiences. Other actors within the TCK industry similarly draw upon their or their children's experiences, with these credentials often being highlighted as part of the services they offer. Here expertise is produced through knowing the emotions associated with being globally mobile as a child—-this is a way in which the TCK industry acts a form of the psy-disciplines in that it makes the TCK knowable through tacit knowledge.

Through this we can see how the TCK industry claims authority on knowing the TCK experience, with this acting as the way through which individuals are persuaded towards the 
Self-Help and the Surfacing of Identity: Producing the Third Culture Kid

identity of TCK. However, as will be shown in the next section, it is through the force of giving a previously unknown emotional experience a name and description (c.f. Ahmed, 2006) that the subject position of the TCK can be offered by self-help.

\section{Surfacing of the TCK}

The rest of this paper takes up the question of the significance of the emotionality of belonging to look at how the TCK industry produces grief and insecurity as being the normal emotional response to childhood global mobility. Following Ahmed (2014) in thinking about how these emotions are circulated, it looks at how these emotions work to 'surface' the collective body of the TCK: it is through emotions, or how we respond to objects and others, that surfaces and boundaries are made' (p. 9). Ahmed illustrates how emotions are relational as they shape 'the surfaces of individual and collective bodies. Bodies take the shape of the very contact they have with objects and others' (p. 1). One example she uses to explore this is a reading of hate in Aryan nation propaganda, whereby the object of hate is produced as a figure that 'works to stick or bind the imagined subjects and white nation together' as an 'us' rather than 'them' (Ahmed, 2014, p. 2). Significantly, this is a way of organising bodies, a way in which categories are made through emotions: it is through affective encounters that objects and others are perceived as having attributes, which 'gives' the subject an identity which is apart from others' (Ahmed, 2014, p. 8). In Ahmed's example, hate surfaces the figure of the stranger as a threat to the nation. In this respect, the focus is on the 'significance of expressed emotions', or the significance of expressing emotions, particularly the role that they play through their naming and explanation (Ahmed, 2014, p. 13). As the section will argue, it is the naming of a normal emotional response to global mobility that surfaces the TCK as a self. 
Self-Help and the Surfacing of Identity: Producing the Third Culture Kid

The TCK, someone who has been brought up internationally, is contrasted by the industry to someone who has grown up in what is labelled a monocultural environment - a place where the majority of people are of a single nationality and similar background. Specifically, two characteristics of a TCK upbringing are portrayed as being different. First, their childhoods are characterised by frequent mobility, either through moving themselves to new locations, or the mobility of others that they know. Second, that living 'between' cultures in their developmental years means that they do not have 'ownership' in any (TCK book, Pollock \& Van Reken, 2009). This portrayal of TCKs as being different from their home country peers is important as it results in a representation of TCKs as having unique emotional problems related to their upbringing: 'when someone asks us what, despite the many benefits, we see as the main challenges TCKs and ATCKs face, we answer, "Finding a sense of personal and cultural identity and dealing with unresolved grief" (TCK book, Pollock \& Van Reken, 2009, p. 64; emphasis in original).

The negative emotions that the industry associate with having been globally mobile as childgrief and insecurity - are seen as a response to a liminality of the self in terms of a national identity. Like other examples of self-help (Rimke, 2000; Sothern, 2007), the TCK industry produces a norm of experience, the monocultural childhood to which the TCK experience is contrasted. The liminal self becomes a 'condition of ambiguity' associated with a globally mobile childhood, one that results from 'being outside the cultural fames of reference' (Butcher, 2011, pp. 7,8 ) of one's national identity. The liminal self is seen as a loss-a loss of the potential self growing up in the monocultural environment which now cannot be realised. By producing the self as being liminal, the TCK industry also produces the self as needing to be discovered, as Rimke highlights: 'Knowledge about the self derived from self-help techniques is assumed to be foremost a matter of discovering who and what one is' or the 'real self' (2000, p. 70$)$. The real self then becomes the TCK, offered through a guided management of emotions. 
Self-Help and the Surfacing of Identity: Producing the Third Culture Kid

To provide an example, we can see how this works through 'insecurity,' which is expressed through the proclaimed difficulty, or 'dread' that TCKs have in answering classic small talk questions: 'There are several questions many TCKs have learned to dread. Among them are these two: "Where are you from?" and "Where is home?" (TCK book, Pollock \& Van Reken, 2009, p. 123). The anxiety that these questions cause TCKs is seen to derive from two reasons.

First, the TCK industry suggests that people who are TCKs are unable to answer this question. They argue that people who have had globally mobile childhoods find it difficult to express where they are from as the question is asking them to frame this in nationalistic terms. For example, an American passport holder, who has spent his childhood living in France, Kuwait and Japan, doesn't feel as if they are American, French, Kuwaiti or Japanese, they 'belong in all of them and none of them' (Field notes from event, March 2015). Due to their frequent mobility, between or 'across' cultural contexts, this also means that they are not seen to belong in the places in which they live: 'the world of rapid cultural change has been their norm as they exchange complete sets of worldviews, expectations of behaviour, and even languages, with an overnight airplane ride' (The TCK book, Pollock \& Van Reken, 2009, p. 45). Lijadi and Van Schalkwyk (2017) have recently argued that TCKs' 'sense of belonging is constantly being challenged from a very young age as the general public often interprets only a single fragment of the TCKs' identity (their passport country) as representative of the whole person while disregarding all other parts of their life experiences' ( $\mathrm{p} 120)$. This feeling of not belonging is emotionally challenging. For example, in the book club discussion about the first chapter of the TCK book, this is very clearly highlighted: 'The pain point of TCKs is identified on the first page: "feeling of not fully belonging anywhere in the world". Having experienced this feeling, even fleetingly, causes us to ask deep questions about identity' (MK and TCK Book Club, Chapter 1, May 2015, Message 2). As this is the first point of discussion, the feeling of pain due to an 
Self-Help and the Surfacing of Identity: Producing the Third Culture Kid

insecurity of identity is produced as being a normal emotional response from the outset of reading the book.

The second cause of dread that the TCK industry argues is derived from the question 'where are you from' is how others respond to one's answer. One way in which this occurs is through a questioning of the respondent because they do not fit with (often raced) assumptions about what someone from that location should look like: 'Fellow students would ask, "Where are you from? At first Erika [an American, so assumed white] automatically answered, "Singapore." The universal reply was, "Really, you don't look like it"” (TCK book, Pollock \& Van Reken, 2009, p. 9). This additional questioning is again seen to make the TCK feel insecure, because they are made to feel that they don't fit, they are made to feel abnormal. This abnormality manifests itself in a second way, through a complexity of the response. Instead of being able to respond with a single answer, for example, 'America,' the respondent feels different because their answer is more complicated. Some go as far to suggest that other people will either find this arrogant, or simply not be interested, with a suggestion that the TCK should 'Think ahead of time how you will answer the question "where are you from?" in a way that won't tire you or freak others out' (TCK book on University Transitions, Quick, 2010, p. 2083). Again, we see discussions of this in response to the TCK book that highlight negative emotions associated with this insecurity, in this case anger: "when asked that question... Rarely do I find locals "wanting to actually know..." that someone could have actually grown up in China or Fiji or Iran... Finally, I always resented when I DID tell them that I grew up overseas... and their response was, "Why? Didn't you like the USA?" So before I would deck the person [a few times it made me angry]' (MK and TCK Book Club, Chapter 9, July 2015, Message 5).

From this, we can see how the TCK industry produces one of the responses to having been globally mobile as a child as an insecurity of (national) identity. This manifests itself emotionally as a feeling that one does not belong, that one is abnormal. This pain, hurt, anger and dread as 
Self-Help and the Surfacing of Identity: Producing the Third Culture Kid

described above is a response to the liminal self, the insecurity of identity. This liminality of the self becomes something that needs to be cured, with some in the TCK industry going as far as to suggest that this is acting potentially as a cure to suicide: 'With this book in mind and, stories of hopelessness and suicidal thinking like the one you read in the introduction [account of a TCK with a depression] need not be repeated' (TCK book on University Transitions, Quick, 2010, p. 392).

Working as a form of self-help, the industry therefore helps individuals who have been globally mobile as children diagnose why they feel insecure about themselves. For people who have had a globally mobile childhood, and dread being asked 'where are you from,' the TCK industry gives them a reason to explain why they feel the way they do, undermining any other reason that might help explain this. For example, Natalie, who found out about TCKs from a social media group, suggested 'it explained a lot of the emotions and feelings I felt of not fitting in most of the time' (Survey response, August 2015). In this way, the labelling of emotions involved in the TCK experience is part of 'naming' the TCK as a category of identification.

The TCK industry then draws up the normal emotional response of a TCK to their globally mobile childhood, with people who share this experience becoming a TCK. It is through the identification of the emotions shared with others who have had a similar experience that the TCK as an identity is surfaced, an 'a-ha' moment of identification: 'I had several "Aha" moments while reading this book' (Anil, January 2007). This is something that the readers of the book are directed towards by the authors: 'the original TCK profile had continued to generate the countless "a-ha" moments we had watched over and over again... Our files were filled with letters from TCKs and their families who had read our book...thanking us for giving language and understanding to an experience lived but, to that point, unnamed for them' (TCK book, Pollock \& Van Reken, 2009, p. xii). A-ha moments can be simultaneously seen as the diagnosis of the cause of the liminal self, but also the cure, the 'discovery' that you are a TCK. It is the way 
Self-Help and the Surfacing of Identity: Producing the Third Culture Kid

in which the TCK industry, the authority figures on knowing the emotional experience of having had a globally mobile childhood, surfaces the TCK as an identity.

\section{Identification as TCK}

With the surfacing of the TCK in response to a recognition of the insecurity and grief of globally mobile childhood experiences, the identification with this becomes understood as comfort. The moment of discovery of the TCK self is something that is referenced repeatedly by those engaging with the industry. For example, 'Byet' references the importance of labelling in his response: 'I am a TCK myself and the first time I read this book I cried and cried because I finally had a name for what I had experienced growing up and realised I wasn't alone' (Amazon Review, July 2011). Isabella, on reading an article about TCKs, expressed her 'amazement that someone was putting words on feelings I hadn't fully articulated' (Survey response, July 2015). Christine discusses the reconciliation that she felt when she found out about TCKs: 'I cried when I read this book. I couldn't believe that there were so many people who were just like me. I did fit in. I fit into the TCK world and all the feelings I grew up with were explained in the pages. For the first time, I felt peace. I knew who I was and why' (Good Reads, April 2013). Comfort then, in reaction to grief and insecurity, is a way through which the TCK as a subject is identified — it is relief, amazement, peace. It is how the 'self' of the reader is produced and given a name-the TCK.

The prescriptive affective response to engaging with the TCK industry is therefore one where the reader undergoes a process of self-discovery-it is a therapeutic experience in itself. This idea of an experience was articulated by those who attended TCK industry events: 'It was a singularly magical experience to be immersed in a community that understood my feelings' (Newsletter, June 2015). An experience speaks to the distinction between the ordinary and extraordinary (Urry \& Larsen, 2011), however as Anderson (2013) highlights, an experience is 
Self-Help and the Surfacing of Identity: Producing the Third Culture Kid

seen to dislocate individuals from their everyday lives and change them. Although writing about surfing, Anderson illustrates how it has a transformative effect, giving the participants an experience that challenges, enthrals and humbles them. Engaging with the TCK industry can be seen in similar terms, as it emotionally challenges and changes the reader, transforming their grief and insecurity into comfort, changing their liminal self into the TCK. For example, 'A reader' highlights this change in a context from feeling lost to finding peace: 'I saw myself in those pages, and it brought to me a sense of peace and astonishment I have never felt before or since...For anyone who feels lost or awkward or helpless, homeless, rootless, and restless, this book is for you' (Amazon Review, June 2010). The 'discovery' that they are a TCK, then, is seen to almost have a spiritual, or what the person writing in the newsletter describes as 'magical', effect on those who have been globally mobile as children. It moves the reader from feelings of being abnormal to having a shared emotional experience. In this way, it changes the reader from being abnormal to normal: 'I finally felt like I have been reached. I belong somewhere. Understood. Accepted. Uplifted. Affirmed' (Elle, Amazon Reviews, January 2006).

The TCK is not just surfaced as an individual self, but as a community. This community aspect is significant in the production of TCKs as people who feel that they do not belong to national cultures; belonging is 'about feeling 'at home' and 'secure', but it is also about being recognised and understood' (Wood \& Waite, 2011, p. 201). Part of the TCK community is a community of feeling, an idea of not being alone with the grief and insecurity associated with having been globally mobile as child: 'After reading this book, I realize there is nothing wrong with me. The first time I read this book, I laughed and cried. It brought up so many emotions within me. I finally realized I was not alone in what I was feeling' (Heather, Amazon Review, August 2006). A shared release from the experience of grief and insecurity becomes a way in which the TCK industry operates—for example, I was asked if I had cried 'yet' at a TCK industry event (Field notes, March 2015). While the person who has been globally mobile as a child is argued not to 
Self-Help and the Surfacing of Identity: Producing the Third Culture Kid

feel as if they belong to the 'first' or 'second' culture, they find a sense of belonging in the 'third:' 'the magical connection...that happens when TCKs meet is more than a sharing of these facts alone. There is something about growing up in and among many cultures that creates an emotional experience and bind that transcends the details' (TCK book, Pollock \& Van Reken, 2009, p. 18).

TCKs are seen to identify with other TCKs, regardless of their background, producing a shared notion of belonging. For example, returning to the set of vignettes based on experience in the TCK book, one night 'Erika' goes to the theatre where she meets 'Judy', another ATCK who 'genuinely wanted to know' about all the places she had lived. Despite very different backgrounds, they 'were soon talking and laughing together like long-lost friends' (TCK book, Pollock \& Van Reken, 2009, pp. 24, 25). Therefore, TCKs are produced again as being different from people with a monocultural background as they are uniquely interested in the background of others. This interest in their lives again has a clear emotional expression for the TCK. We can see this expressed through a reflection of attendance at a TCK event: 'I didn't expect to feel such a connection to many of the stories that speakers and attendees shared - strong sense of belonging. It means more that I realised to be surrounded by my tribe' (Event reflection, Wilson, 2015, p. 26). By becoming a group of people with similar experiences, a new norm is produced of having had globally mobile childhoods. This is a group where individuals can find a sense of peace in belonging. For example, Tae suggests the finding of a TCK community resolved his feelings of 'trauma': 'It gave me some closure in the fact that I was not the only TCK in the world, and that the identity crisis I had felt growing up was totally normal and common' (Amazon Review, August 2013).

Therefore, we can see the way that naming the shared emotional experience of having been globally mobile as a child works to surface the TCK as subject — this is the 'force of being given a name' (Ahmed, 2006, p. 15). It is by following the experts in knowing this experience, that 
Self-Help and the Surfacing of Identity: Producing the Third Culture Kid

individuals are directed to take up this subject position, how it becomes articulated as part of their identity. For those who do identify as a TCK, a feeling of normality or belonging to a group is something that they find comfort in. The TCK industry does this through identification-that it is normal to feel grief and insecure if you have been globally mobile as a child. In this way, selfhelp works to validate people's feelings: 'Well it's the shared experience, the nuancing of the emotional responses, the insights... being seen and understood. What more could a child or adult want' (MK and TCK Book Club, Chapter 2, June 2015, Message 42). In validating what causes these negative feelings, the TCK industry offers the solution - the discovery one is a TCK, and reframing the abnormal subject in the monocultural environment as the normal subject in the 'third' culture.

\section{Conclusions}

In this paper, I have used the case study of the TCK industry to provide an example of how we can understand self-help in the constitution of identities. The paper has illustrated how the production of a normal emotional response to having been globally mobile as a child works to produce the TCK self. It is in this way that the TCK industry, and self-help industry more broadly, can be described as a space of biopower, a space in which emotions as an aspect of life are produced. As the paper has illustrated, it is through a reading of grief, insecurity and comfort, particularly the validation and shared experience of this emotional response to having been globally mobile as a child, that the TCK industry works to produce the TCK as a self. This means the paper contributes to debates about understanding identity, highlighting how self-help acts as a space through which identities are performed and produced. This reading of how the self is governed through the emotions of having been globally mobile as a child therefore highlights how self-help, and categories of identity, come to have meaning in people's lives. 
Self-Help and the Surfacing of Identity: Producing the Third Culture Kid

In thinking about self-help more broadly, the paper has shown a method by which we can move beyond accounts of neoliberal ideas within self-help, to looking at the production and consumption of these ideas. That is, while we can look at what the self is within self-help, this doesn't tell us why people respond to these ideas. Although this paper is by no means suggesting that everyone who has had a globally mobile childhood engages with the TCK industry in the same ways, there is a significant amount of buy in from people-afterall this is what keeps the industry going. Through the paper, I have argued that self-help acts as a form of the psydisciplines, where the authority of knowing the subject acts as the direction towards this. The production of the ideas, in persuading their consumption, becomes as important as the ideas themselves in telling us why people take up the TCK self offered to them.

This also contributes to our understanding of the spatiality of emotional registers of belonging. As Wood and Waite discuss, belonging is about feeling 'at 'home' and 'secure,' but it is equally about being recognised and understood, a process which is often disrupted through migration (2011, p. 201), like that of the TCK. Migration is arguably an emotional experience, a complex negotiation of identity, home and belonging (Boccagni \& Baldassar, 2015). Within research on transnationalism and diaspora, particularly within calls to ground these studies, the ways in which people feel has become an important way through which we think about connections across borders (for example Dunn, 2010). Svašek (2010) highlights that within research on transnational migration we can see two major emotional processes of migrants: attachment to home and interactions that they have with local communities. It is through these types of negotiations that individuals make sense of their identities: 'our sense of who and what we are is continually (re)shaped by how we feel' (Davidson \& Milligan, 2004, p. 524). For example, in thinking about emotional citizenship, Ho (2009) argues this is constituted through a feeling that you belong to a country, through both feeling at home and safe. Askins (2016), expanding on this, illustrates the role that making connections with Others plays in feeling that you belong through encounters. 
Self-Help and the Surfacing of Identity: Producing the Third Culture Kid

However, in general, this research can be seen to reflect a methodological nationalism (Wimmer \& Glick-Schiller, 2002) in the ways through which the emotional register of belonging and identity is understood. That is, belonging as an emotional response is seen to be produced in relation to place-for example to Singapore as a nation in Ho's work and to the making of a new life in the U.K in Askin's. While these types of place attachments are important, this might also obfuscate other sites through which (migrant) emotions, and identities more widely, are produced. TCKs are a group of people who, by virtue of their upbringing, are seen to have identities that are formed through mobility as opposed to place. However, through this paper, I have shown that the TCK is not an axiomatic identity, but becomes an identity that can be consumed through the TCK industry. Part of how this works, is through the production of the TCK as being abnormal in that they do not have a place-based understanding of identity, a kind of methodological nationalism in the TCK industry's thinking. This helps offer us a further critique to the TCK as a categorisation, for example as being 'MacDonaldised' (Benjamin \& Dervin, 2015) and focusing on Westernised, privileged children (Fechter \& Korpela, 2016; Tanu, 2016). The paper has illustrated how the TCK industry works to produce the TCK as a distinct identity, as opposed to this form of belonging being located as emotional attachments to home, host country or hybridity. This shows us how we can move beyond solely place-based accounts of (migrant) identity and include other sites that shape a sense of how people feel, including selfhelp industries.

\section{References}

Ahmed, S., 2006. Queer phenomenology: orientations, objects, others. Durham; London: Duke University Press.

Ahmed, S., 2014. The Cultural Politics of Emotion. 2nd ed. Edinburgh: Edinburgh University Press. Anderson, B., 2011. Affect and biopower: towards a politics of life. Transactions of the Institute of British Geographers, 37(1), pp. 28-43.

Anderson, J., 2013. Cathedrals of the surf zone: regulating access to a space of spirituality. Social and Cultural Geography, 14(8), pp. 954-972. 
Self-Help and the Surfacing of Identity: Producing the Third Culture Kid

Askins, K., 2016. Emotional citizenry: everyday geographies of befriending, belonging and intercultural encounter. Transactions of the Institute of British Geographers, 41(4), pp. 515-527.

Barnes, T., 2002. Performing economic geography: two men, two books, and a cast of thousands. Environment and Planning A, 34(3), pp. 487-512.

Benjamin, S. \& Dervin, F., 2015. Introduction. In: F. Dervin \& S. Benjamin, eds. Migration, Diversity and Education: Beyond Third Culture Kids. London: Palgrave Macmillan , pp. 1-10.

Bertuccelli, D., 2015. Ruth Van Reken. In: J. Parfitt \& J. Dean, eds. Insights and Interviews from the 2014 Families in Global Transition (FIGT) Conference- The Global Family Redefined. United Kingdom : Summertime Publishing, pp. 1-7.

Boccagni, P. \& Baldassar, L., 2015. Emotions on the move: Mapping the emergent field of emotion and migration. Emotion, Space and Society, Volume 16, pp. 73-80.

Butcher, M., 2011. Managing Culture Change: Reclaiming Synchronicty in a Mobile World. Farnham: Ashgate.

Cranston, S., 2016. Producing Migrant Encounter: Learning to be a British Expatriate in Singapore through the Global Mobility Industry, Environment and Planning D: Society and Space 34(4) 655-671

Davidson, J., 2001. 'Joking apart...: a 'processual' approach to researching self-help groups. Social and Cultural Geography, 2(2), pp. 163-183.

Davidson, K. \& Milligan, C., 2004. Embodying emotion sensing space: introducing emotional geographies. Social and Cultural Geography, 5(4), pp. 523-532.

Dunn, K., 2010. Embodied transnationalism: bodies in transnational spaces. Population, Space and Place, 16(1), pp. 1-9.

Eyal, G., 2013. For a Sociology of Expertise: The Social Origins of the Autism Epidemic. American Journal of Sociology, 118(4), pp. 863-907.

Faulconbridge, J., Beaverstock, J., Hall, S. \& Hewitson, A., 2009. The 'war for talent': The gatekeeper role of executive search firms in elite labour markets. Geoforum, 40(5), pp. 800-808.

Fechter, A. \& Korpela, M., 2016. Interrogating child migrants or 'Third Culture Kids' in Asia: An introduction. Asian and Pacific Migration Journal, 25(4), pp. 422-428.

Foucault, M., 2007. Security, Territory, Population: Lectures at the College De France. Houndmills: Palgrave Macmillan .

Hannerz, U., 2003. Being there...and there...and there!: Reflections on Multi-Site Ethnography. Ethnography, 4(2), pp. 201-216.

Hazleden, R., 2003. Love yourself: The relationship of the self with itself in self-help texts. Journal of Sociology, 39(4), pp. 413-428.

Ho, E., 2009. Constituting Citizenship Through the Emotions: Singaporean Transmigrants in London. Annals of the Association of American Geographers, 99(4), pp. 788-804.

Larner, W. \& Le Heron, R., 2002. The spaces and subjects of a globalising economy: a situated exploration of method. Environment and Planning D: Society and Space, 20(6), pp. 753-774. 
Self-Help and the Surfacing of Identity: Producing the Third Culture Kid

Lijadi, A. \& Van Schalkwyk, G., 2017. Place identity construction of Third Culture Kids: Eliciting voices of children with high mobility lifestyle. Geoforum, Volume 81, pp. 120-128.

Mansfield, N., 2000. Subjectivity: Theories of the Self from Freud to Haraway. New York: New York University Press.

Marcus, G., 1995. Ethnography in/of the World System: the emergence of multi-sited ethnography. Annual Review of Anthropology, Volume 24, pp. 95-117.

McGee, M., 2005. Self-Help Inc: Makeover Culture in American Life. Oxford: Oxford University Press.

Ong, A., 2007. Neoliberalism as a mobile technology. Transactions of the Institute of British Geographers, 32(1), pp. 3-8.

Pearce, R., 2015. Afterword. In: S. Benjamin \& F. Dervin, eds. Migration, Diversity, Education: beyond Third Culture Kids. New York: Palgrave Macmillian, pp. 233-248.

Pollock, D. \& Van Reken, R., 2009. Third Culture Kids: Growing Up Among Worlds. 2nd ed. Boston, London: Nicholas Brealey Publishing.

Pollock, D. \& Van Reken, R., 2009. Third Culture Kids: Growing Up Among Worlds. 2nd ed. Boston: London: Nicholas Brealey Publishing .

Pykett, J. \& Enright, B., 2016. Geographies of brain culture: optimism and optimisation in workplace training programmes. cultural geographies, 23(1), pp. 51-68.

Quick, T., 2010. The Global Nomad's Guide to University Transition. Kindle ed. Great Britain: Sumertime Publishing.

Rimke, H., 2000. Governing Citizens Through Self-Help Literature. Cultural Studies, 14(1), pp. 6178.

Rose, N., 1999. Governing the Soul: The Shaping of the Private Self. London; New York: Free Association Books.

Sothern, M., 2007. You could truly be yourself if you just weren't you: sexuality, disabled body space, and the (neo)liberal politics of self-help. Environment and Planning D: Society and Space, 25(1), pp. 114-159.

Sothern, M. \& Dickinson, J., 2011. Repaying the gift of life: self-help, organ transfer and the debt of care. Social and Cultural Geography, 12(8), pp. 889-903.

Svašek, M., 2010. On the Move: Emotions and Human Mobility. Journal of Ethnic and Migration Studies, 36(6), pp. 365-380.

Tanu, D., 2016. Going to school in 'Disneyland': Imagining an international school community in Indonesia. Asian and Pacific Migration Journal , 25(4), pp. 429-450.

Urry, J. \& Larsen, J., 2011. The Tourist Gaze 3.0. London: SAGE Publications.

Van Reken, R., 2012. Letters Never Sent: a global nomad's journey from burt to healing. 2nd edition ed. Colorado Springs, CO: Cook Communications Ministries Intl.

Van Reken, R., 2014. In memory of Davd C. Pollock A man ahead of his time. [Online] Available at: http://news.tckid.com/in-memory-of-david-c-pollock-a-man-ahead-of-his-time- 
Self-Help and the Surfacing of Identity: Producing the Third Culture Kid

guest-post-from-ruth-van-reken/

[Accessed 16 June 2015].

Wilson, T., 2015. Writers in Residence. In: J. Parfitt \& J. Dean, eds. Insights and Interviews from the 2014 Families in Global Transition (FIGT) Conference- The Global Family Redefined. United Kingdom: Summertime Publishing, pp. 25-28.

Wimmer, A. \& Glick-Schiller, N., 2002. Methodological nationalism and beyond: nation-state building, migration and the social sciences. Global networks, 4(301-334), p. 2.

Wood, N. \& Waite, L., 2011. Editorial: Scales of Belonging. Emotion, Space and Society, 4(4), pp. 201-202. 